\title{
REVIEW ARTICLE Ferroptosis in viral infection: the unexplored possibility
}

\author{
Mao-peng Wang ${ }^{1}$, Banda Joshua ${ }^{1}$, Ning-yi $\mathrm{Jin}^{2}$, Shou-wen $\mathrm{Du}^{3}$ and Chang $\mathrm{Li}^{2}$
}

Virus-induced cell death has long been thought of as a double-edged sword in the inhibition or exacerbation of viral infections. The vital role of iron, an essential element for various enzymes in the maintenance of cellular physiology and efficient viral replication, places it at the crossroads and makes it a micronutrient of competition between the viruses and the host. Viruses can interrupt iron uptake and the antioxidant response system, while others can utilize iron transporter proteins as receptors. Interestingly, the unavailability of iron facilitates certain viral infections and causes cell death characterized by lipid peroxide accumulation and malfunction of the antioxidant system. In this review, we discuss how iron uptake, regulation and metabolism, including the redistribution of iron in the host defense system during viral infection, can induce ferroptosis. Fenton reactions, a central characteristic of ferroptosis, are caused by the increased iron content in the cell. Therefore, viral infections that increase cellular iron content or intestinal iron absorption are likely to cause ferroptosis. In addition, we discuss the hijacking of the iron regulatoy pathway and the antioxidant response, both of which are typical in viral infections. Understanding the potential signaling mechanisms of ferroptosis in viral infections will aid in the development of new therapeutic agents.

Keywords: viral infections; cell death; ferroptosis; iron; antioxidant response

Acta Pharmacologica Sinica (2022) 43:1905-1915; https://doi.org/10.1038/s41401-021-00814-1

\section{INTRODUCTION}

The incidences of emerging and re-emerging viral infections have surged despite the tremendous progress in preventing and controlling infectious diseases and the biomedical field for the past two decades. The occurrence of epidemics and pandemics, such as the Ebola virus [1], Influenza virus [2], middle east respiratory syndrome coronavirus (MERS-CoV) [3], severe acute respiratory syndrome coronavirus (SARS-CoV) [4], and SARS-CoV-2 [5] has posed a significant threat to humans. Several animal viruses, such as african swine fever virus [6], inflict significant economic loss. Virus infections have been shown to trigger cell death via various mechanisms, depending on the viral species, however elucidating the causes and effects can be difficult [7-9]. Cell death can be a double-edged sword during pathogenic infections $[10,11]$. On the one hand, virus-associated cell death can help to prevent additional infection, while on the other hand, it contributes to the progression of many infections [10, 12-14]. On another facet, viral infection can lead to cell death due to viral activities within infected cells $[15,16]$, and the escape of viral progeny can cause cell death $[15,17]$. It is noteworthy that some viruses encode proteins to inhibit cell death and facilitate their proliferation $[7,8]$.

Iron is an essential element for many enzymes in the cell. These enzymes include but are not limited to DNA primase, DNA helicases, ribonucleotide reductase, and ATPase [18], which are necessary for DNA expression. The unavailability of iron compromises multiple cellular functions, including genome replications [19]. The vital role of iron in cellular physiology maintenance and efficient viral genome replication places iron at the crossroads and makes it a competing chemical between the pathogen and the host [20, 21]. During infections, the immune response fortifies its defense in which iron is withheld from pathogens $[22,23]$. However, various viral species have been found to interrupt iron uptake and the antioxidant response system [21], while others utilize iron transporter proteins as receptors (see Table 1). Interestingly, an increase in iron concentration facilitates ferroptosis.

Ferroptosis is a regulated cell death pathway that heavily depends on iron-mediated lipid free radical formation and accumulation $[24,25]$. These actions can be inhibited by the enzyme glutathione peroxidase 4 (GPX4) and the antioxidant glutathione (GSH). Interruption of the cellular process that leads to ferroptosis can inhibit its occurrence [24-26]. Therefore, this interruption can serve as a therapeutic method to manipulate cells by either increasing their survivability or inducing death in infection conditions. Here, we review how iron uptake, regulations, and metabolism, including the redistribution of iron in the host defense system during viral infection, can induce ferroptosis. Described herein also is the inhibition of the antioxidant response during infections, emphasizing GSH and GPX4 as these are identified major inhibitors of ferroptosis.

\section{FERROPTOSIS}

Ferroptosis, as proposed by the Nomenclature Committee on Cell Death (NCCD), is a mechanism of cell death resulting from oxidative perturbations of the intracellular microenvironment, which is under

\footnotetext{
${ }^{1}$ Wenzhou Key Laboratory for Virology and Immunology, Institute of Virology, Wenzhou University, Chashan University Town, Wenzhou 325000, China; ${ }^{2}$ Research Unit of Key

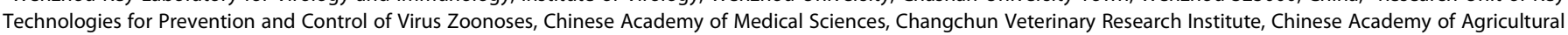

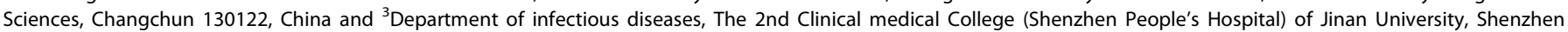
518020, China

Correspondence: Shou-wen Du (du-guhong@163.com) or Chang Li (lichang78@163.com)
}

Received: 1 July 2021 Accepted: 1 November 2021

Published online: 6 December 2021 
Table 1. Effects of viruses on iron metabolism and the possible contribution to ferroptosis.

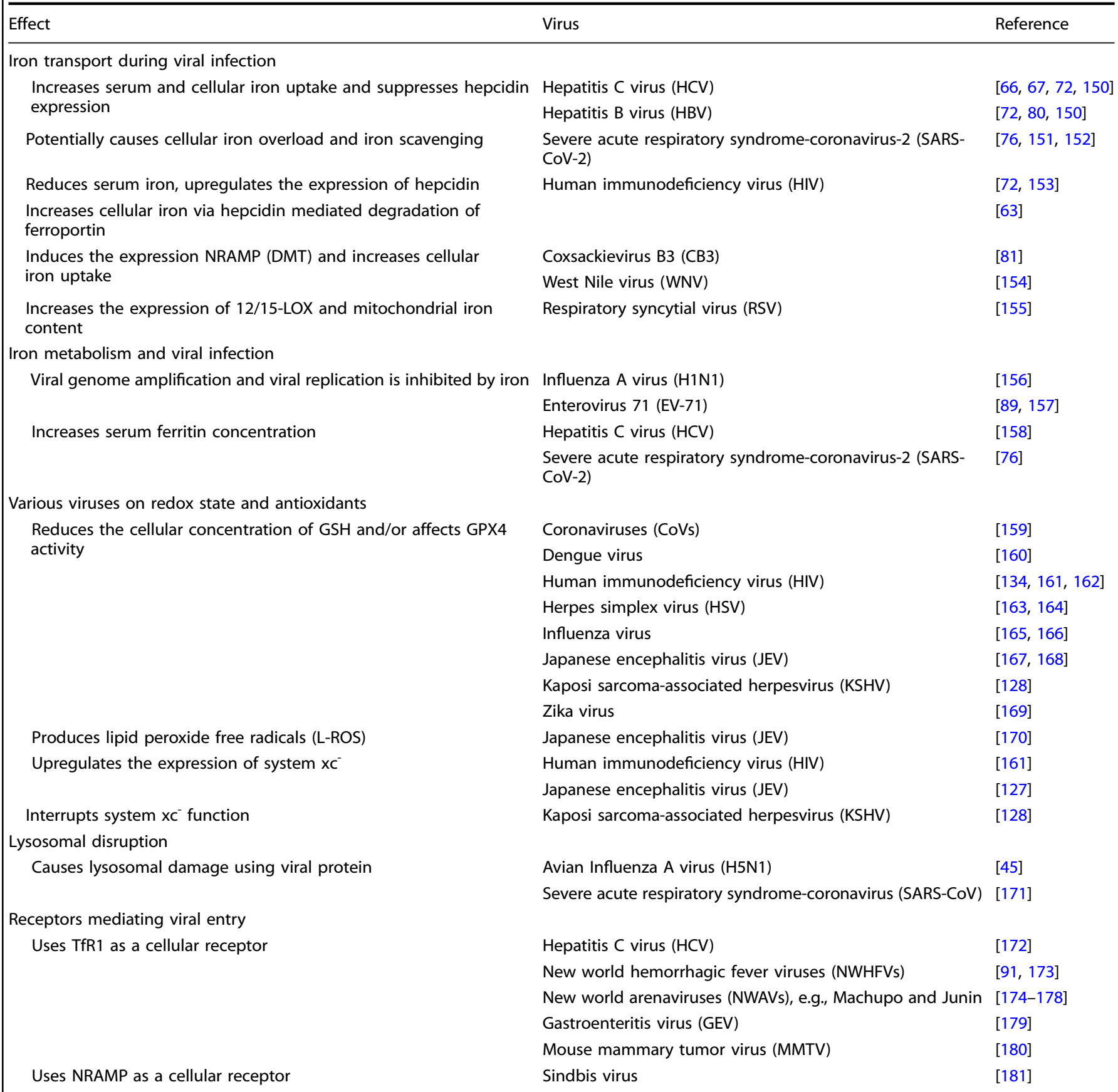

constitutive regulation by GPX4 [25], which is heavily marked by iron driven lipid peroxidation (Fig. 1) and lipotoxicity accumulation due to Fenton reactions and failure of the antioxidant defense to inhibit or terminate the pathway. Dixon et al. [24] observed that ferroptosis is distinct from other forms of cell death in many facets. Morphologically, it is marked by small mitochondria with a higher membrane density, reduced or absent mitochondrial crista, and raptured out membranes $[24,27]$. These changes may be controlled by the $\mathrm{BH} 3$-interacting domain death antagonist (BID) and $\mathrm{BCL} 2$ binding component 3 (PUMA) $[28,29]$. Reportedly, the cell nucleus during ferroptosis does not change in size [30] but can be electronlucent [31]. The integrity of the nuclear membrane is jeopardized, causing the release of High Mobility Group-Box 1 (HMGB1). Suggestively, the nucleus membrane damage may be caused by lipid peroxides, and the damage may extend as far as the inner membrane [31]. Biochemically, ferroptosis is marked by the depletion of GSH and reduced GPX4 activity and lipotoxicity [27]. Genetical changes that may alter iron homeostasis and facilitate lipid peroxidation, the two main features of ferroptosis, are also involved. However, it is worth noting that the process is regulated by multiple genes associated with iron uptake, lipotoxicity, and antioxidation responses. (Further reading on genes that regulate ferroptosis $[24,32-37])$.

\section{IRON UPTAKE}

Stable iron ion homeostasis is vital for cell function and survival. Iron in the body can be acquired by absorption in the intestine or 


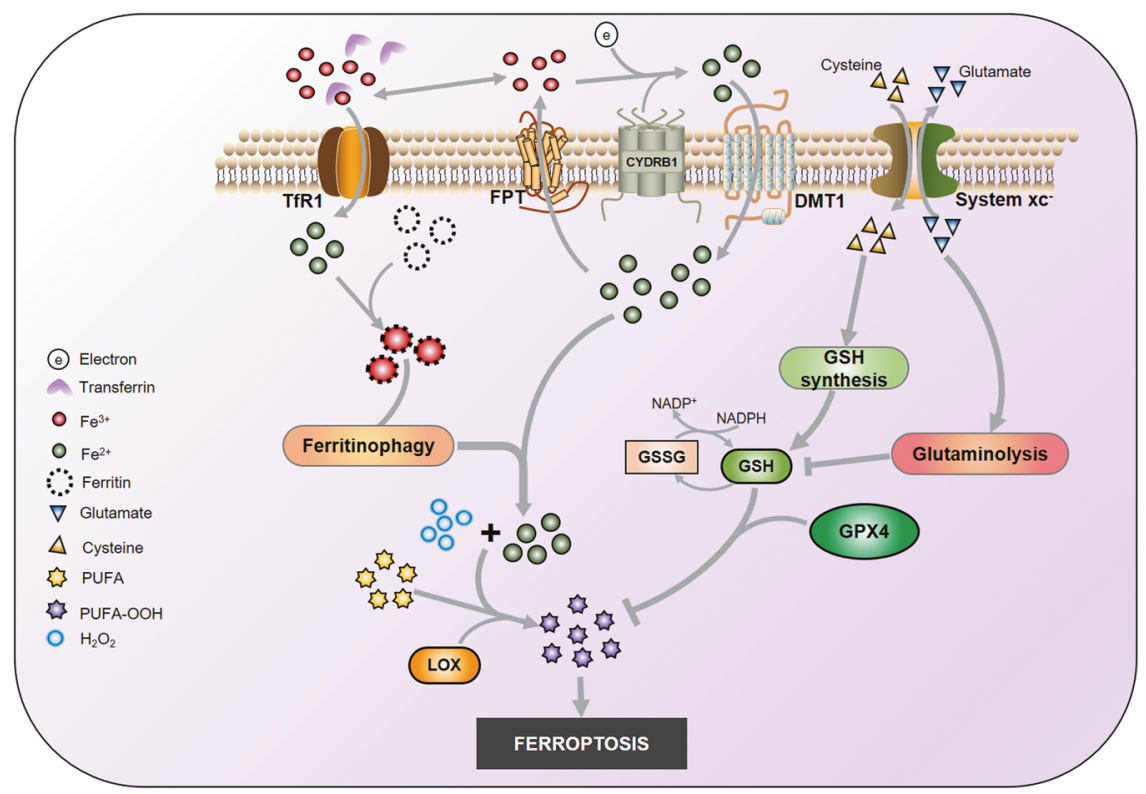

Fig. 1 Ferroptosis inducing pathways. Iron enters the cell via TfR1 or DMT1 and is exported by FPT. DMT1 uptakes Fe ${ }^{2+}$ and requires CYDRB1 to reduce $\mathrm{Fe}^{3+}$. When inside the cell, iron binds to ferritin, which can be degraded by a lysosomal activity known as ferritinophagy. Non-ferritin iron can then react with $\mathrm{O}_{2}$ molecule, e.g., $\mathrm{H}_{2} \mathrm{O}_{2}$ the by-products of this reaction then reacts with PUFAs forming lipid peroxides. System-xc imports cysteine and exports glutamate. Cysteine is used in the synthesis of GSH, which, together with GPX4, reduces lipotoxicity. Glutamate participates in glutaminolysis. GSH can be inhibited by downstream metabolites of glutaminolysis. An increase of iron or inhibition of GSH/ GPX4 results in ferroptosis. TfR1 Transferrin receptor protein 1, DMT1 divalent metal transporter, FPT ferroportin, CYDRB1 Cytochrome B Reductase 1, PUFAs short for polyunsaturated fats, GSH Glutathione, GSSG Glutathione disulfide, GPX4 Glutathione Peroxidase 4, LOX Lysyl Oxidase.

Box 1 The emerging role of organelles and signaling pathways in ferroptosis

Lack or depletion of functional mitochondria disrupts cellular sensitivity to cysteine depletion or deprivation [56]. The hyperpolarization of the mitochondrial outer membrane potential can cause the depletion of GSH via deprivation of cysteine [56], which can facilitate cysteine deprivation-dependent ferroptosis while inhibiting cellular cysteine uptake. The mitochondrial promotes the exhaustion of GSH, thereby attenuating the antioxidant mechanism [182] Disruption of mitochondrial processes, TCA cycle, electron transport chain and glutaminolysis, has been reported to inhibit ferroptosis [56, 118, 182]. On top of this, mitochondrial lipids serve as a source for lipid peroxides [56].

Lysosomes are no bystanders in ferroptosis. Lysosomal activity influences iron availability in the cell by disrupting transferrin transport and degradation of ferritin $[183,184]$. In addition, the lysosomal activity also produces ROS, inclusive of lipid peroxides. Autophagic activities mediated by the lysosome are likely to participate in ferroptosis, as shown by studies [43, 185]. Cysteine deprivation significantly reduces following the knockdown of autophagic genes ATG3 and ATG13 [43]. Autophagy is also likely to cause ROS accumulation and induction of ferroptosis [36]. Lysosomal cathepsin B has also been known to induce GSH depletion. STAT3 is an activator of cathepsin B and can therefore participate in ferroptosis [36, 43].

The endoplasmic reticulum may also play a role in ferroptosis as inducers of ferroptosis cause ER stress [118]. Erastin-induced ER stress activates the ATF4 signaling pathway, and the downstream of the pathway promotes degradation of GSH [186]. The role of ER and ER stress remains highly uninvestigated. However, ER stress promotes autophagy [187], and autophagy can degrade ferritin, causing ferroptosis.

Signaling pathways that may inhibit system xc- or increase cellular iron availability are also likely to cause ferroptosis. The heme oxygenase 1 (HO-1) [188], HSPB1 [48], and FANCD2 [189] pathways influence iron availability and have been linked to ferroptosis. FANCD2 targets genes involved in iron metabolism and GPX4, leading to iron increase while reducing the antioxidant effect. p53 [190] and its activator G3BP1-interacting IncRNA [191] facilitate ferroptosis by targeting the SLC7A11 component of the system xc- thereby attenuating its function.

from the degradation of erythrocytes. Intestinal iron uptake involves haem iron transporter HEPH, DMT1, FPN1, and TfR1. Intestines are a major source of iron. Iron uptake in the intestine is heavily influenced by the microbiota and is absorbed in $\mathrm{Fe}^{2+}$. Ferrous is transported into the cell via the TfR1 receptor protein.
ZRT/IRT-like proteins have also been identified as transporters of $\mathrm{Fe}^{2+}$ that are not bound to transferrin $[38,39]$. While inside the cell, $\mathrm{Fe}^{3+}$ is encapsulated in the acidic endosome, where it is reduced back to $\mathrm{Fe}^{2+}$ by the six-transmembrane epithelial antigen of the prostate 3 (STEAP3), which also facilitates TfR1 dependent iron uptake [40] or stored in ferritin [41]. From here, the iron is then released into the cytoplasm with the help of divalent metal transporter 1 (DMT1) (DMT1 is also present on the plasma and organelle membranes) for usage or balancing iron deficiency. Iron is exported out of the cell via ferroportin (FPT), an iron efflux pump that can oxidize $\mathrm{Fe}^{2+}$ to $\mathrm{Fe}^{3+}[42]$.

The inhibition of iron export and/or the increase in uptake promotes ferroptosis. Processes that increase free iron content in the cell, such as ferritinophagy, which is the degradation of ferritin leading to the release of iron into the cytosolic labile iron pool, promote iron accumulation and is reported to induce ferroptosis [43] (Fig. 1). Ras mutation also causes ferroptosis by increasing the expression of TfR 1 while reducing the expression of ferritin [44]. The degradation of organelles that have high deposits of iron, such as lysosome [45] and mitochondria [46], can also cause cytosolic iron increase and thereby leading to ferroptosis (Box 1). The accumulated iron can react with lipids forming lipid reactive species while inhibition of iron accumulation in the cell attenuates ferroptosis [24, 47, 48].

\section{LIPID PEROXIDATION}

Iron-mediated lipid peroxidation occurs mainly using the polyunsaturated fatty acids (PUFA), which are susceptible to peroxidation due to their acyl tail. PUFA phospholipids can be generated by the enzymes Acyl-CoA synthetase long-chain family member 4 (ACSL4) and lysophosphatidylcholine acyltransferase 3 (LPCAT). LPCAT is also responsible for PUFA activation and remodeling into transmembrane lipid $[49,50]$. Aside from this, PUFAs can also be obtained from dietary sources or synthesized by the enzyme acetyl CoA carboxylase. These phospholipids require esterification 


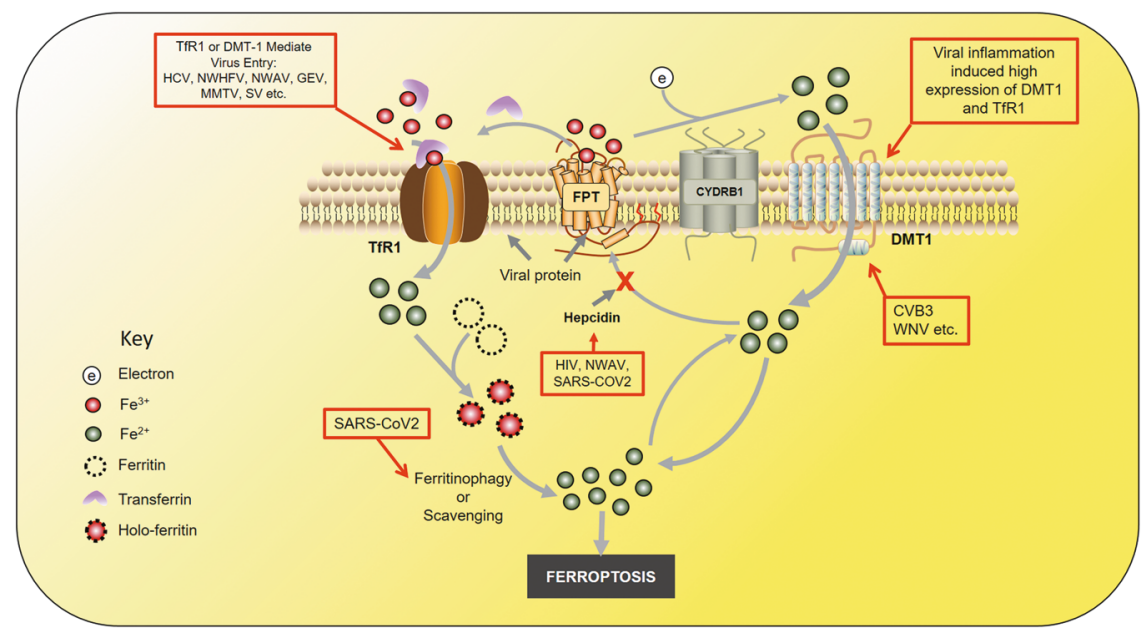

Fig. 2 Viruses, iron, and iron receptors. Iron transport proteins such as TfR1 and DMT1 serve as receptors of many viruses. TfR 1 and DMT1 are upregulated by a viral infection, causing increased iron uptake. Iron-bound in ferritin is scavenged by viruses via viral-induced ferritin degradation or disruption. Viral activity causes hepcidin expression, which inhibits iron export and leads to excessive cellular iron. These eventually cause cell death via ferroptosis. TfR1 Transferrin receptor protein 1, DMT1 divalent metal transporter, FPT ferroportin, CYDRB1 Cytochrome B Reductase 1.

and oxidation to function as a synthetic signal transduction medium [51]. Reportedly the oxygenation attack occurs on the acyl-arachidonoyl (AA) and the adrenoyl acid (AdA) phosphatidylethanolamine (PE) end of the lipid chain [52]. This oxygenation can be directly achieved by 12/15-lipoxygenases (12/15-LOX), cytochrome P450 oxidoreductase, as well as other iron-containing sources of oxidation such as AKR1C1-3 [27, 53-55]. The oxygenated PE then functions as death signals and causes the depletion of PE and other PUFAs [53]. When iron in the cytoplasm reacts with $\mathrm{H}_{2} \mathrm{O}_{2}$ (Fenton reaction), producing $\mathrm{OH}$, which attacks PUFAs (Fig. 1), a chain reaction that produces lipid peroxides starts [24]. Aside from this, iron is a cofactor of enzymes that catalyze lipid peroxidation $[51,55]$. Lipid peroxidation can also occur in the lysosome [43] as well as the mitochondrial [56] (Box 1).

\section{ANTIOXIDANTS}

The suppression of GPX4 activity leaves lipid peroxidation unchecked and facilitates ferroptosis, achieved by RSL3/5, ML162, ML210 DPIs, and FIN02, etc., which can interfere with the GPX4 [26, 27, 47]. GPX4 activity can also be inhibited by buthionine sulphoximine (BSO), which terminates the synthesis of GSH [27], and FIN56, which causes a short supply of selenocysteine tRNA by inhibiting the melanovate pathways, attenuats GPX4 synthesis [57, 58]. FIN56, together with acetylCoA carboxylase, can also degrade GPX4 [52]. The melanovate pathway is likely to play a role in the inhibition of ferroptosis due to its production of ferrostatin and liproxstatin, which reduces lipotoxicity [26, 47]. The downregulation of GPX4 has been shown to increase cell sensitivity to ferroptosis [44]. Other molecules known to induce ferroptosis via direct or indirect induction are artesunate, lanperisone, and acetaminophen $[59,60]$. The voltage-dependent ion channel proteins 1 and 3 (VDAC1/3) of the outer membrane of the mitochondria can cause the exhaustion of cysteine and, therefore, may likely cause cysteine deprivation [30]. Gao et al. reported the mitochondria as an antagonist of antioxidants in ferroptosis [56].

\section{VIRUSES, IRON METABOLISM AND FERROPTOSIS}

Iron regulation and viral infection

Hepcidin, a key protein to regulate systematic iron homeostasis, binds to the iron transporting protein ferroportin causing its internalization and degradation (Fig. 2), resulting in an increase in the cytoplasmic iron and a negative regulatory effect on iron uptake $[61,62]$. Degradation of ferroportin can facilitate viral genome transcription as observed in HIV-1 [63]. The expression of hepcidin is modulated by the increase in iron availability due to intestinal absorption or the release from macrophages iron recycling, a cellular increase of iron stores, inflammation, or infection. Many viral infections have shown an inverse relationship between the increase in cellular iron endosomes and hepcidin upregulation [64]. An increase of hepcidin is accompanied by high ferritin, thereby storing iron in an inactive state. The cell is deprived of iron and is protected from further infection and the production of free radicals [65].

Contrary to this, research in chronic hepatitis $\mathrm{C}$ viral (CHCV) infection reports differently as hepcidin is downregulated instead of upregulated [66]. This dysregulation causes the systematic increase of ferritin in the blood and transferrin saturation, which has been attributed as a major contributing factor to the accumulation of iron in hepatic cells during CHCV infection, the progression of the infection as well as its resistance to treatment [66-68]. Iron released into circulation via ferroportin during recycling can cause serum iron overload [69, 70]. The host response to viral infection by redistributing iron makes it prone to co-infection by other pathogens. Joann and the team reported the subsequent association between HIV-induced iron redistribution and tuberculosis [71]. High cellular iron concentration can induce hepcidin expression. Possibly, virally infected cells experience increased iron uptake before the hepcidin expression is elevated, and viruses have been known to produce proteins that target regulatory proteins of iron metabolism, such as TfR1 (Fig. 2), which has been reported in HIV infections but is not investigated in other viral infections [72-74]. Certain viruses have also been found to hijack cells that are actively taking in iron [21]. Ameglio and the team reported the downregulation of ferritin two days postinfection due to viral replication in HeLa-derived cells RD, C8166, and HeLa-T4-6c [75]. The team also suggested that this possibly causes iron toxicity.

On the contrary, in a surveying study on COVID-19 patients, it was observed that there was a high concentration of serum ferritin in patients who had pronounced inflammatory responses [76]. However, ferritin may serve as a source of iron, while some viral protein may scavenge iron or interfere with hepcidin activity [77] (Fig. 2). Iron scavenging and toxicity have been elucidated in 


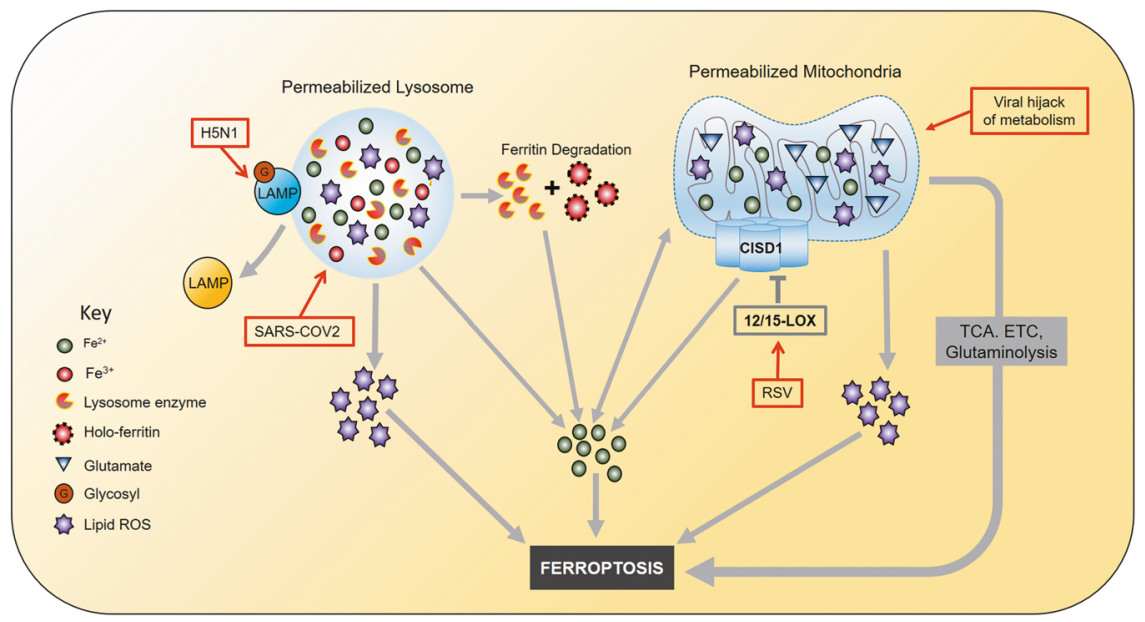

Fig. 3 Iron-rich organelles in viral infection. The iron in lysosomes and mitochondria with permeabilized membranes is released into the cytosol, causing cytosolic iron accumulation. Lysosomes and mitochondria can also be a source of lipid ROS. 12/15 LOX inhibits CISD1, which increases mitochondrial iron uptake consequently. 12/15 LOX is upregulated during RSV infection. Viruses hijack cell metabolism and increase the TCA cycle, ETC activity, and glutaminolysis which facilitates ferroptosis. H5N1 can deglycosylate LAMP, thereby disrupting or permeabilizing the lysosome and causes lysosomal content leakage. Lysosomal enzymes degrade ferritin causing further accumulation of iron. The iron can then participates in lipid peroxidation, or the lysosome/mitochondria lipid ROS causes ferroptosis. ROS Reactive oxygen species, CISD1 CDGSH Iron Sulfur Domain 1, LOX Lysyl Oxidase, LAMP Lysosomal Associated Membrane Protein, TCA cycle tricarboxylic acid cycle, ETC Electron Transport Chain, RSV Respiratory Syncytial Virus.

bacterial infections but are not highly investigated in viral infection [77-79], further suggesting the need to investigate iron uptake and ferritin in various viral infections prior to and post increased hepcidin expression. The accumulation of cellular iron due to viral infection can cause Fenton reactions and finally ferroptosis. (Further reading on Viruses and Iron [22, 80-87]).

Inhibition of viral infection depending on iron

In mammals, blood hosts an abundant supply of iron. This iron is either free or binds to haeme. Iron can regulate the replication of numerous viral infections in different organisms. In humans, iron inhibits the replication of the hepatitis $C$ virus by suppressing viral RNA and protein expression via inhibiting the nonstructural protein 5B (NS5B) polymerase [88]. Ferriccontaining salts such as ferric ammonium citrate (FAC) have also been shown to inhibit other viruses, including Influenza A virus, Zika virus, EV-71, HIV [89]. However, this inhibition depends not just on the iron contained in the salt but also on the citrate. Organisms that acquire nutrition from other organisms via blood meals obtain most of their iron from these blood meals. Mosquitoes are one kind of such an organism, and Zhu and coworkers found that the prevalence of dengue virus in the mosquito was regulated by the host serum iron [90]. The host serum iron was utilized by the iron metabolism pathway of the mosquitoes to inhibit viral ROS generation, thereby reducing viral infectivity. (Further reading on viruses and iron metabolism proteins $[77,91-95])$.

Iron receptors and transport proteins usage by viruses

Iron receptors on cells of different organisms have also been known to serve as entry points of viruses (Table 1, Fig. 2). The natural resistance-associated macrophage protein (NRAMP), a common iron receptor in Drosophila and $A$. aegypti was found to be the serve receptor of Sindbis virus, and its downregulation due to iron supplements resulted in the inhibition of the viral replication in a research study by Hitoshi and the team [96]. TfR1 in mammals has also been identified as receptors of several viral species, including but not limited to New World hemorrhagic fever viruses, Machupo virus, Junin virus, Canine Parvovirus, Mouse mammary tumor virus [91, 97]. Some viruses like the coxsackievirus B3 tend to facilitate the expression of proteins involved in cellular iron uptake, such as metallothionein $1 / 3$ and DMT1 upon early days of infections [81].

\section{VIRUSES, IRON RICH ORGANELLE, AND FERROPTOSIS}

Viral activities such as viral gene expression, host-virus triggered signaling, virus-physiological stress, among others, can destroy organelles of the host. The destruction of cellular organelles that abundant house iron-containing or iron-requiring proteins such as lysosome and mitochondria results in releasing the iron into the cytosol. The organelle contents are likely to participate in ferroptosis or infection progression (Fig. 3).

\section{The mitochondria}

The mitochondria possess a high iron content, as is required in the ATP synthesis during the electron transporting process. Exogenous factors, including viral infections, have been known to induce loss of mitochondrial membrane potential (MMP) [98, 99]. MMP can cause leakage of many mitochondrial contents, which may disrupt many cellular processes. Although there is no research showing the link between viral infection and the release of mitochondrial iron, recent findings suggest that this is likely to occur when the mitochondria membrane integrity is jeopardized $[100,101]$. Investigations in this area may provide new therapeutic targets and further understand why viral infections are worsened in older people. Iron uptake by the mitochondria increases with age, and this may cause iron overload [46]. Reportedly iron overload causes leakage of mitochondrial oxidants and ROS [102]. Mitochondrial ROS has been known to inhibit hepcidin transcription, leading to iron accumulation [100, 103]. Iron can then participate in lipid peroxidation and eventually cause ferroptosis cell death. Notably, in some viral infections, mitochondrial damage seems to be inhibited [100]. Alternatively, with the depletion of GSH and the inactivity of GPX4, 12/15-lipoxygenase (12/15-LOX) can be activated in the mitochondria to oxidize PUFAs $[55,104,105]$. Activated 12/15-LOX has been reported to oxidize mitochondria membrane lipids in neuronal cells [105], which causes the accumulation of lipid peroxides in the mitochondrial membrane. 12/15-LOX activation has also been known to increase mitochondrial iron content via its inhibition of the CDGSH iron-sulfur domain 1 (CISD1) $[105,106]$. CISD1 plays a key 


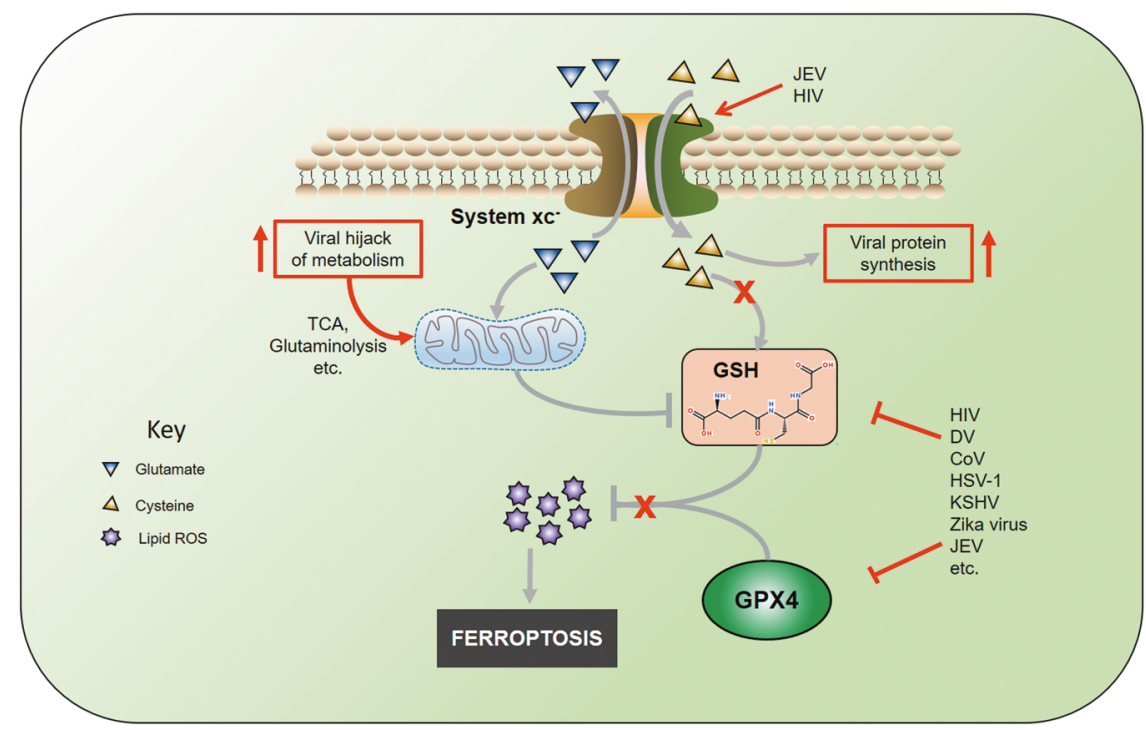

Fig. 4 Antioxidants of ferroptosis during viral infection. System- $\mathrm{xc}^{-}$influxes cysteine and effluxes glutamate. Cysteine is used in viral protein synthesis, causing reduced GSH synthesis. Viruses inhibit GPX4 and GSH by either attenuating synthesis or degrading the protein and molecule. Virally hijacked metabolism produces metabolites that inhibit or degrade GSH. Lack of antioxidant activity leads to the accumulation of lipid ROS and eventually causes ferroptosis. GSH Glutathione, GPX4 Glutathione Peroxidase 4, ROS Reactive oxygen species, TCA tricarboxylic acid.

role in the modulation of iron uptake by the mitochondria, and its loss of function increases iron content $[107,108]$. This iron can cause Fenton reactions in the mitochondria or can be released in an event where the mitochondria membrane integrity is jeopardized. Yuan et al. reported that the inhibition of CISD1 contributes to mitochondrial lipid peroxidation and eventually ferroptosis [109]. Certain viruses hijack the mitochondria to evade the mitochondrial antiviral signaling and replication [110], and this may cause hyperpolarization, which can impair the antioxidant mechanism [56].

\section{Lysosomes}

Lysosomes have been long known to contain a relatively large amount of redox-active iron due to their role in iron metabolism [111, 112]. Lysosomal damage can occur in viral infections, resulting in the release of lysosomal content, including redox-active iron. Xiangwu and the team found that the neuraminidase (NA) of the H5N1 influenza virus can degrade and deglycosylate the lysosomal associated membrane protein (LAMP) (see Fig. 1) [45]. Lysosomal enzymes are often glycosylated to prevent the hydrolysis of lysosomal environment content $[113,114]$. The deglycosylation effect of NA on LAMP, which makes up at least $50 \%$ of the lysosome membrane content, can cause digestion and rapture of the lysosome membrane (see Table 1) [45]. Reportedly this can cause the release of lysosomal content inclusive of hydrolytic enzymes and the high content of iron which is often present in the lysosomal, thereby leading to an increase in the cytosolic iron labile pool $[45,115]$. The accumulated iron can then mediate Fenton lipid peroxidation. Iron catalyzed lipid peroxidation in the absence of reductants and causes lipid peroxide accumulation, leading to cell death.

Furthermore, the released lysosome enzymes can degrade the ferritin via proteolytic methods. Ferritin is degraded by the lysosome to supplement cellular iron deficiency or in an autophagic manner by the process of ferritinophagy using lysosome enzymes [116]. The autophagy degradation of ferritin has been reported to cause ferroptosis [36]. Suggestively, permeabilization of the lysosome is likely to cause the release of enzymes involved in ferritin degradation and the degradation of proteins involved in iron regulation into the cytosol, which can increase the cytosolic iron ion content leading to the dysregulation of iron metabolism. Lysosomal permeabilization can induce or participate in multiple cell death mechanisms, including but not limited to lysosomal dependent cell death, necrosis, necroptosis, and apoptosis [117]. Other viruses have been known to induce lysosome permeabilization, although the mechanism remains unclear [115].

\section{VIRUSES, ANTIOXIDANTS, AND FERROPTOSIS}

System- $\mathrm{Xc}^{-}$antiport and cysteine

The cysteine can be prevented from entering the cell by blocking or inhibiting the cysteine/glutamate antiporter system-xc or preventing the participation of cysteine in GSH formation. Inducers of ferroptosis include but are not limited to glutamate, erastin sulfasalazine, and sorafenib. These molecules can directly interfere with the activity of system $\mathrm{xc}^{-}$thereby interrupting the supply of cysteine and consequently damages the endoplasmic reticulum $[24,118,119]$. The supply of cysteine is essential in the synthesis of GSH [120]. Jiang L and Sato have reported P53's ability to repress cysteine absorption via the downregulation of SLC7A11, a key active component of the system-xc ${ }^{-}[121,122]$. This process is, however, dependent on the presence of ROS-induced stress [123]. System- $\mathrm{xc}^{-}$functions involve the influx of cysteine in the cytosol and the efflux of glutamate into the extracellular space [124]. The released glutamate represents the principal source of extracellular glutamate in brain regions and causes excitotoxicity implicated in several neuronal diseases $[125,126]$. Certain viruses such as the Japanese encephalitis virus have been known to enhance the system-xc ${ }^{-}$activity and therefore facilitate neuronal damage, but this also has been found to reduce oxidative stress in the cells [127]. Research by Dai and coworkers reported reducing intracellular GSH and inducing viral lytic gene expression following the inhibition of system-xc in PEL cells infected with the Kaposi's sarcoma-associated herpesvirus (KSHV) [128]. In the same research, it was suggested that the inhibitors of system-xc' can prevent PEL tumor progression. The inhibition of the antiporter results in the reduction of GSH synthesis, GPX activity and weakens the antioxidant defense. There is limited knowledge on the role and state of system-xc antiport in viral infection. However, current data suggest that inhibiting the antiport can facilitate ferroptosis. Suggestively as most viruses incorporate 
Box 2 GPX4 in antiviral innate immunity

While GPX4 function has been mainly attributed to reducing oxidized molecules, it is noteworthy that GPX4 also plays a role in the innate immune system. Research by Matsushita and the team reported that the absence of GPX4 in antigen-specific T cells (CD8 ${ }^{+}$and $\mathrm{CD}^{+}$) altered the physiological response of the T cells [192]. This alternation was manifested in the form of the failure to expand and protect from acute lymphocytic choriomeningitis virus (LCMV). GPX4 was therefore found to be crucial in the expansion of the T cell and the protection of viral and parasitic infections. Notably, GPX4 is required for T cell survival under noninflammatory conditions [192]. However, the requirement for survivability may differ among the subsets of T cells. GPX4 deficient T cells died via ferroptosis, and this prevented immunity to infection by LCMV. Returning normal functionality and increased survivability were observed in cells under lipid peroxyl stress after treatment with Vitamin E [192]. Vitamin E is known to be an inhibitor of ferroptosis due to its antioxidant activity and has been shown to improve cell survival in GPX4 deficient cells $[192,193]$. GPX4 also indirectly activates the stimulator-ofinterferon genes (STING), which is important in sensing foreign nucleic acid material in the cytoplasm. This activation is achieved by maintaining the redox state of the cell. Jia et al. reported the carbonylation of STING in HSV, which was facilitated by GPX4 deficiency and is inhibited by GPX4 [194]. In the same experiment, the inhibition of STING by GPX4 reduced HSV infection. The role that GPX4 plays in the immune system is not well elaborated and may require further investigation. There is supporting evidence that low levels of GPX4 can exacerbate infections by enhancing cell death and altering the function of the T cells. (Further reading on GPX4 in the immune system [194-197]).

cysteine in their protein, it is likely to occur that the antiport can maintain its function during viral infection, yet the antioxidant response is jeopardized.

Glutathione and GPX4

Glutathione (GSH), a molecule that plays a key role in the cellular response to ROS and their elimination. It is formed by glutamatecysteine synthetase by covalently combining cysteine and glutamate. In this process, cysteine is the rate-limiting reactant, and its absence reduces the cells' capability to respond to ROS effects $[120,129]$ (Fig. 4). Cysteine enters the cell via the system $x c^{-}$. GSH often detoxifies hydrogen peroxide $\left(\mathrm{H}_{2} \mathrm{O}_{2}\right)$, which is often involved in many reactions that produce ROS, including Fenton reactions. Enzymes of the GPX family then use GSH as a substrate to reduce $\mathrm{H}_{2} \mathrm{O}_{2}$ into water producing a hydroxyl $\left(\mathrm{OH}^{-}\right)$molecule, which oxidizes GSH and forms GSSG. GSSG is not an antioxidant and requires to be reduced to GSH to function as an antioxidant, achieved by using NADPH as a cofactor, and the enzymes glutathione reductase (GSR) catalyzes the reaction, which yields GSH and $\mathrm{NAD}^{+}[120,129,130]$. Unfortunately, the oxidation and reduction of GSH can produce excess free radicals that damage molecules (via oxidation) that play critical roles in cellular homeostasis [131].

ROS in a cell can have beneficial functions as signal molecules in immune response [132]. Different viruses may have various ways by which they can induce ROS and lead to its accumulation. These ROS targeting antioxidant defense proteins are often inclusive of the GPX family of enzymes [133]. Morris et al. reported low cellular GSH in macrophages with an increased concentration of GSSG in HIV infection [134] (see Table 1), and a higher concentration of free radicals, pro-inflammatory cytokines were observed. Aside from the ROS oxidation of GSH to form GSSG, the production of pro-inflammatory cytokines such as IL-1 can cause the depletion of cysteine concentration in the cell [135]. Cysteine depletion can also be attributed to the excessive and rapid incorporation of cysteine in the viral genome RNA proteins, which have several cysteine amino acids containing domains, which occurs mainly during viral replication and contributes to a decrease in GSH $[136,137]$. In response to the inflammation and depletion of cysteine, key enzymes in the synthesis of GSH are downregulated [138-140], which impairs the antioxidant function of GSH and its availability, leading to cellular loss of GPX4 function. As established earlier, GPX4 is identified as a key enzyme in response to lipid peroxidation and an inhibitor of ferroptosis. The lack of GSH will cause GPX4 inactivity, and this, therefore, can promote cell death by ferroptosis due to the accumulation of lipid-free radicals or lipid peroxides. Some studies found that GPX4 expression, together with other selenoproteins, was reduced due to HIV infection [141], which may require further investigation into other viruses. On top of this, ROS molecules produced during viralinduced inflammation may facilitate ferroptosis. Interestingly, some viruses can encode GPX4 in their genome, as observed in the human dermatotropic poxvirus [142]. GPX4 is not only essential in the antioxidant mechanism but also the immune system (Box 2).

\section{CONCLUSION AND PERSPECTIVES}

Viruses are no strangers to hijacking and disrupting multi-cellular processes to favor their proliferation, which can have unfavorable consequences on host cells and lead to cell death. Various mechanisms of cell death have been observed in many viral infections. A recently described mechanism of cell death, ferroptosis, is likely to be among the forms of cell death during viral infections. Common features of ferroptosis, such as reduced cysteine and consequently reduced GSH, reduced GPX4 activity, and increased cellular iron availability, among others, have been found to occur in viral infections, suggesting the possible occurrence of ferroptosis, especially when occurring together with dysregulated cell metabolism. However, it is noteworthy that the induction and process may differ from one virus to another, and some viruses may not cause ferroptosis. Iron is essential for viral replication, which may be the reason for the viral usage of iron transporters as receptors, while the underlying mechanism that viruses interrupt iron metabolism remains elusive.

Gut which serves as a major site for dietary iron uptake and a site for iron regulation by hepcidin, and the role of microbiota in iron uptake during viral infections may also provide new insights. Certain viruses target intestinal enterocytes as primary cells of infection. Advances in understanding the mechanism of ferroptosis and discovering new inducers have revealed the role of metabolites and cellular organelles in ferroptosis. Viruses have been known to disrupt cell metabolism and organelles, leading to conditions that may favor ferroptosis. Further investigations in cellular metabolism during viral infections and how it may facilitate ferroptosis can also provide a new understanding. An increased focus on how ferroptosis occurs in viral infections and understanding the role of microbiota in iron uptake during viral infections may lead to discovering new therapeutic targets.

Furthermore, therapeutics of iron metabolism may serve as potential drugs to inhibit viral infection exacerbation caused by cell death. Currently, there are many types of medicines regulating ferroptosis by enzyme inhibition, ion chelation and redox response [143]. Canonical antioxidants, like butylated hydroxytoluene or vitamin $E$, are recognized as both modulators of ferroptosis and supplements fighting against SARS-CoV-2, HSV, HIV, etc. [144-146]. Among these iron-dependent drugs, most of them variously show antiviral activity for certain viral species. However, the precise antiviral mechanism still need further investigations to provide significant research data. Increasing discoveries prove that ferrous-reactive endoperoxides like artemisinin, arterolane, and artefenomel also have an antiviral function [147-149]. The pharmacological intervention of the ferropotosis pathway indicates promising therapeutics for virus infection prevention and control. The decipherment of the regulatory process of ferroptosis is still critical and can ultimately facilitate the development of new antiviral drugs.

\section{ACKNOWLEDGEMENTS}

This work was supported by the National Natural Science Foundation of China [No.31802224]; Jilin University Science and Technology Innovative Research Team 
(JLU-STIRT) [2017TD-05]; CAMS Innovation Fund for Medical Sciences (2020-12M-5001). This review should not be taken as evidence of ferroptosis in viral infection but can be referenced for investigations in these or any related areas. The mentioned viruses are not the only viruses that can increase the likelihood of ferroptosis in host cells. The authors' views are of the authors and should not be interpreted as expressions or implications of the affiliated institutes.

\section{ADDITIONAL INFORMATION}

Competing interests: The authors declare no competing interests.

\section{REFERENCES}

1. Olival KJ, Hayman DT. Filoviruses in bats: current knowledge and future directions. Viruses. 2014;6:1759-88.

2. Neumann G, Noda T, Kawaoka Y. Emergence and pandemic potential of swineorigin H1N1 influenza virus. Nature. 2009;459:931-9.

3. Memish ZA, Mishra N, Olival KJ, Fagbo SF, Kapoor V, Epstein JH, et al. Middle East respiratory syndrome coronavirus in bats, Saudi Arabia. Emerg Infect Dis. 2013;19:1819-23.

4. Khan G. A novel coronavirus capable of lethal human infections: an emerging picture. Virol J. 2013;10:66.

5. Jiang S, Xia S, Ying T, Lu L. A novel coronavirus (2019-nCoV) causing pneumoniaassociated respiratory syndrome. Cell Mol Immunol. 2020;17:554.

6. Dixon LK, Stahl K, Jori F, Vial L, Pfeiffer DU. African swine fever epidemiology and control. Annu Rev Anim Biosci. 2020;8:221-46.

7. Danthi P. Viruses and the diversity of cell death. Annu Rev Virol. 2016;3:533-53.

8. Brune W, Andoniou CE. Die Another Day: Inhibition of Cell Death Pathways by Cytomegalovirus. Viruses. 2017:9:249.

9. Castillo JA, Urcuqui-Inchima S. Mechanisms of monocyte cell death triggered by dengue virus infection. Apoptosis: Int J Program Cell Death. 2018; 23:576-86.

10. Jorgensen I, Rayamajhi M, Miao EA. Programmed cell death as a defence against infection. Nat Rev Immunol. 2017;17:151-64.

11. Ashida H, Mimuro H, Ogawa M, Kobayashi T, Sanada T, Kim M, et al. Cell death and infection: a double-edged sword for host and pathogen survival. J Cell Biol. 2011;195:931-42.

12. Naidoo J, Wang $X$, Woo KM, lyriboz T, Halpenny D, Cunningham J, et al. Pneumonitis in patients treated with anti-programmed death-1/programmed death ligand 1 therapy. J Clin Oncol. 2017;35:709-17.

13. Grywalska E, Pasiarski M, Sosnowska-Pasiarska B, Macek P, Rolińska A, Samardakiewicz $M$, et al. Programmed cell death 1 expression and Epstein-Barr virus infection in chronic lymphocytic leukaemia: a prospective cohort study. Cancer Manag Res. 2019;11:7605-18.

14. Legrand AJ, Konstantinou M, Goode EF, Meier P. The diversification of cell death and immunity: memento mori. Mol Cell. 2019;76:232-42.

15. Downey J, Pernet E, Coulombe F, Divangahi M. Dissecting host cell death programs in the pathogenesis of influenza. Microbes Infect. 2018;20:560-9.

16. Atkin-Smith GK, Duan M, Chen W, Poon IKH. The induction and consequences of Influenza A virus-induced cell death. Cell Death Dis. 2018;9:1002.

17. Kabiljo J, Laengle J, Bergmann M. From threat to cure: understanding of virusinduced cell death leads to highly immunogenic oncolytic influenza viruses. Cell Death Discov. 2020;6:48.

18. Zhang C. Essential functions of iron-requiring proteins in DNA replication, repair and cell cycle control. Protein Cell. 2014;5:750-60.

19. Puig S, Ramos-Alonso L, Romero AM, Martinez-Pastor MT. The elemental role of iron in DNA synthesis and repair. Metallomics. 2017;9:1483-500.

20. Schaible UE, Kaufmann SH. Iron and microbial infection. Nat Rev Microbiol. 2004;2:946-53.

21. Drakesmith $\mathrm{H}$, Prentice A. Viral infection and iron metabolism. Nat Rev Microbiol. 2008;6:541-52

22. Weinberg ED. Iron withholding: a defense against viral infections. Biometals. 1996:9:393-9.

23. Ganz T, Nemeth E. Iron homeostasis in host defence and inflammation. Nat Rev Immunol. 2015;15:500-10.

24. Dixon SJ, Lemberg KM, Lamprecht MR, Skouta R, Zaitsev EM, Gleason CE, et al. Ferroptosis: an iron-dependent form of nonapoptotic cell death. Cell. 2012;149:1060-72.

25. Galluzzi L, Vitale I, Aaronson SA, Abrams JM, Adam D, Agostinis P, et al. Molecular mechanisms of cell death: recommendations of the Nomenclature Committee on Cell Death 2018. Cell Death Differ. 2018;25:486-541.

26. Yang WS, SriRamaratnam R, Welsch ME, Shimada K, Skouta R, Viswanathan VS, et al. Regulation of ferroptotic cancer cell death by GPX4. Cell. 2014; 156:317-31.
27. Friedmann Angeli JP, Schneider M, Proneth B, Tyurina YY, Tyurin VA, Hammond VJ, et al. Inactivation of the ferroptosis regulator Gpx4 triggers acute renal failure in mice. Nat Cell Biol. 2014;16:1180-91.

28. Neitemeier S, Jelinek A, Laino V, Hoffmann L, Eisenbach I, Eying R, et al. BID links ferroptosis to mitochondrial cell death pathways. Redox Biol. 2017;12:558-70.

29. Hong SH, Lee DH, Lee YS, Jo MJ, Jeong YA, Kwon WT, et al. Molecular crosstalk between ferroptosis and apoptosis: emerging role of ER stress-induced p53independent PUMA expression. Oncotarget. 2017;8:115164-78.

30. Yagoda N, von Rechenberg M, Zaganjor E, Bauer AJ, Yang WS, Fridman DJ, et al. RAS-RAF-MEK-dependent oxidative cell death involving voltage-dependent anion channels. Nature. 2007:447:864-8.

31. Miyake S, Murai S, Kakuta S, Uchiyama $Y$, Nakano $H$. Identification of the hallmarks of necroptosis and ferroptosis by transmission electron microscopy. Biochem Biophys Res Commun. 2020;527:839-44.

32. Wang Y, Yang L, Zhang X, Cui W, Liu Y, Sun QR, et al. Epigenetic regulation of ferroptosis by H2B monoubiquitination and p53. EMBO Rep. 2019;20:e47563.

33. Ou Y, Wang SJ, Li D, Chu B, Gu W. Activation of SAT1 engages polyamine metabolism with p53-mediated ferroptotic responses. Proc Natl Acad Sci USA. 2016;113:E6806-12

34. Xie Y, Zhu S, Song X, Sun X, Fan Y, Liu J, et al. The Tumor Suppressor p53 Limits Ferroptosis by Blocking DPP4 Activity. Cell Rep. 2017;20:1692-704.

35. Sun X, Ou Z, Chen R, Niu X, Chen D, Kang R, et al. Activation of the p62-Keap1NRF2 pathway protects against ferroptosis in hepatocellular carcinoma cells. Hepatology. 2016;63:173-84.

36. Hou W, Xie Y, Song X, Sun X, Lotze MT, Zeh HJ, et al. Autophagy promotes ferroptosis by degradation of ferritin. Autophagy. 2016;12:1425-8.

37. Lin CC, Mabe NW, Lin YT, Yang WH, Tang X, Hong L, et al. RIPK3 upregulation confers robust proliferation and collateral cystine-dependence on breast cancer recurrence. Cell Death Differ. 2020;27:2234-47.

38. Gálvez-Peralta M, He L, Jorge-Nebert LF, Wang B, Miller ML, Eppert BL, et al. ZIP8 zinc transporter: indispensable role for both multiple-organ organogenesis and hematopoiesis in utero. PLoS One. 2012;7:e36055.

39. Zhao N, Gao J, Enns CA, Knutson MD. ZRT/IRT-like protein 14 (ZIP14) promotes the cellular assimilation of iron from transferrin. J Biol Chem. 2010;285:32141-50.

40. Ohgami RS, Campagna DR, Greer EL, Antiochos B, McDonald A, Chen J, et al. Identification of a ferrireductase required for efficient transferrin-dependent iron uptake in erythroid cells. Nat Genet. 2005;37:1264-9.

41. Bradley JM, Le Brun NE, Moore GR. Ferritins: furnishing proteins with iron. J Biol Inorg Chem. 2016;21:13-28.

42. Miller LD, Coffman LG, Chou JW, Black MA, Bergh J, D'Agostino R Jr, et al. An iron regulatory gene signature predicts outcome in breast cancer. Cancer Res. 2011;71:6728-37.

43. Gao M, Monian P, Pan Q, Zhang W, Xiang J, Jiang X. Ferroptosis is an autophagic cell death process. Cell Res. 2016;26:1021-32.

44. Yang WS, Stockwell BR. Synthetic lethal screening identifies compounds activating iron-dependent, nonapoptotic cell death in oncogenic-RAS-harboring cancer cells. Chem Biol. 2008;15:234-45.

45. Ju X, Yan Y, Liu Q, Li N, Sheng M, Zhang L, et al. Neuraminidase of Influenza A virus binds lysosome-associated membrane proteins directly and induces lysosome rupture. J Virol. 2015;89:10347-58.

46. Gao X, Qian M, Campian JL, Marshall J, Zhou Z, Roberts AM, et al. Mitochondrial dysfunction may explain the cardiomyopathy of chronic iron overload. Free Radic Biol Med. 2010:49:401-7.

47. Cao JY, Dixon SJ. Mechanisms of ferroptosis. Cell Mol Life Sci. 2016;73:2195-209.

48. Sun X, Ou Z, Xie M, Kang R, Fan Y, Niu X, et al. HSPB1 as a novel regulator of ferroptotic cancer cell death. Oncogene. 2015;34:5617-25.

49. Doll S, Proneth B, Tyurina YY, Panzilius E, Kobayashi S, Ingold I, et al. ACSL4 dictates ferroptosis sensitivity by shaping cellular lipid composition. Nat Chem Biol. 2017;13:91-8.

50. Hashidate-Yoshida T, Harayama T, Hishikawa D, Morimoto R, Hamano F, Tokuoka SM, et al. Fatty acid remodeling by LPCAT3 enriches arachidonate in phospholipid membranes and regulates triglyceride transport. eLife. 2015;4:e06328.

51. Yin $\mathrm{H}, \mathrm{Xu} \mathrm{L}$, Porter NA. Free radical lipid peroxidation: mechanisms and analysis. Chem Rev. 2011;111:5944-72.

52. Kagan VE, Mao G, Qu F, Angeli JP, Doll S, Croix CS, et al. Oxidized arachidonic and adrenic PEs navigate cells to ferroptosis. Nat Chem Biol. 2017:13:81-90.

53. Dixon SJ, Winter GE, Musavi LS, Lee ED, Snijder B, Rebsamen M, et al. Human haploid cell genetics reveals roles for lipid metabolism genes in nonapoptotic cell death. ACS Chem Biol. 2015;10:1604-9.

54. Zou Y, Li H, Graham ET, Deik AA, Eaton JK, Wang W, et al. Cytochrome P450 oxidoreductase contributes to phospholipid peroxidation in ferroptosis. Nat Chem Biol. 2020;16:302-9.

55. Yang WS, Kim KJ, Gaschler MM, Patel M, Shchepinov MS, Stockwell BR. Peroxidation of polyunsaturated fatty acids by lipoxygenases drives ferroptosis. Proc Natl Acad Sci USA. 2016;113:E4966-75. 
56. Gao M, Yi J, Zhu J, Minikes AM, Monian P, Thompson CB, et al. Role of mitochondria in ferroptosis. Mol Cell. 2019;73:354-63 e3.

57. Warner GJ, Berry MJ, Moustafa ME, Carlson BA, Hatfield DL, Faust JR. Inhibition of selenoprotein synthesis by selenocysteine tRNA[Ser]Sec lacking isopentenyladenosine. J Biol Chem. 2000;275:28110-9.

58. Kryukov GV, Castellano S, Novoselov SV, Lobanov AV, Zehtab O, Guigó R, et al. Characterization of mammalian selenoproteomes. Science. 2003;300:1439-43.

59. Eling N, Reuter L, Hazin J, Hamacher-Brady A, Brady NR. Identification of artesunate as a specific activator of ferroptosis in pancreatic cancer cells. Oncoscience. 2015;2:517-32.

60. Lorincz T, Jemnitz K, Kardon T, Mandl J, Szarka A. Ferroptosis is involved in acetaminophen induced cell death. Pathol Oncol Res. 2015;21:1115-21.

61. Nemeth E, Tuttle MS, Powelson J, Vaughn MB, Donovan A, Ward DM, et al. Hepcidin regulates cellular iron efflux by binding to ferroportin and inducing its internalization. Science. 2004;306:2090-3.

62. Hentze MW, Muckenthaler MU, Andrews NC. Balancing acts: molecular control of mammalian iron metabolism. Cell. 2004;117:285-97.

63. Xu M, Kashanchi F, Foster A, Rotimi J, Turner W, Gordeuk VR, et al. Hepcidin induces HIV-1 transcription inhibited by ferroportin. Retrovirology. 2010;7:104.

64. Moreira AC, Mesquita G, Gomes MS. Ferritin: An Inflammatory Player Keeping Iron at the Core of Pathogen-Host Interactions. Microorganisms. 2020;8:589.

65. Kernan KF, Carcillo JA. Hyperferritinemia and inflammation. Int Immunol. 2017; 29:401-9.

66. Girelli D, Pasino M, Goodnough JB, Nemeth E, Guido M, Castagna A, et al. Reduced serum hepcidin levels in patients with chronic hepatitis C. J Hepatol. 2009:51:845-52.

67. Fujita N, Sugimoto R, Takeo M, Urawa N, Mifuji R, Tanaka H, et al. Hepcidin expression in the liver: relatively low level in patients with chronic hepatitis $\mathrm{C}$. Mol Med. 2007;13:97-104.

68. Fujita N, Sugimoto R, Urawa N, Araki J, Mifuji R, Yamamoto M, et al. Hepatic iron accumulation is associated with disease progression and resistance to interferon/ribavirin combination therapy in chronic hepatitis C. J Gastroenterol Hepatol. 2007;22:1886-93.

69. Donovan A, Brownlie A, Zhou Y, Shepard J, Pratt SJ, Moynihan J, et al. Positional cloning of zebrafish ferroportin1 identifies a conserved vertebrate iron exporter. Nature.2000;403:776-81.

70. McKie AT, Marciani P, Rolfs A, Brennan K, Wehr K, Barrow D, et al. A novel duodenal iron-regulated transporter, IREG1, implicated in the basolateral transfer of iron to the circulation. Mol Cell. 2000;5:299-309.

71. McDermid JM, Hennig BJ, van der Sande M, Hill AV, Whittle HC, Jaye A, et al. Host iron redistribution as a risk factor for incident tuberculosis in HIV infection: an 11-year retrospective cohort study. BMC Infect Dis. 2013;13:48.

72. Armitage AE, Stacey AR, Giannoulatou E, Marshall E, Sturges $P$, Chatha $K$, et al. Distinct patterns of hepcidin and iron regulation during HIV-1, HBV, and HCV infections. Proc Natl Acad Sci USA. 2014;111:12187-92.

73. Babiker ZO, Wingfield T, Galloway J, Snowden N, Ustianowski A. Extreme elevation of ferritin and creatine kinase in primary infection with HIV-1. Int J STD AIDS. 2015;26:68-71.

74. Drakesmith H, Chen N, Ledermann H, Screaton G, Townsend A, Xu XN. HIV-1 Nef down-regulates the hemochromatosis protein HFE, manipulating cellular iron homeostasis. Proc Natl Acad Sci USA. 2005;102:11017-22.

75. Ameglio F, Tilocca F, Arca MV, Alemanno L, Dolei A. Ferritin downregulation in HIV-infected cells. AIDS Res Hum Retroviruses. 1993;9:795-8.

76. Zhou F, Yu T, Du R, Fan G, Liu Y, Liu Z, et al. Clinical course and risk factors for mortality of adult inpatients with COVID-19 in Wuhan, China: a retrospective cohort study. Lancet. 2020;395:1054-62.

77. Parrow NL, Fleming RE, Minnick MF. Sequestration and scavenging of iron in infection. Infect Immun. 2013;81:3503-14.

78. Larson JA, Howie HL, So M. Neisseria meningitidis accelerates ferritin degradation in host epithelial cells to yield an essential iron source. Mol Microbiol. 2004;53:807-20.

79. Whitby PW, VanWagoner TM, Springer JM, Morton DJ, Seale TW, Stull TL. Burkholderia cenocepacia utilizes ferritin as an iron source. J Med Microbiol. 2006;55:661-8.

80. Felton C, Lustbader ED, Merten C, Blumberg BS. Serum iron levels and response to hepatitis B virus. Proc Natl Acad Sci USA. 1979;76:2438-41.

81. Ilbäck NG, Frisk P, Mohamed N, Gadhasson IL, Blomberg J, Friman G. Virus induces metal-binding proteins and changed trace element balance in the brain during the course of a common human infection (coxsackievirus B3) in mice. Sci Total Environ. 2007;381:88-98.

82. Karupiah G, Harris N. Inhibition of viral replication by nitric oxide and its reversal by ferrous sulfate and tricarboxylic acid cycle metabolites. J Exp Med. 1995;181:2171-9.

83. Weinberg ED. Iron depletion: a defense against intracellular infection and neoplasia. Life Sci. 1992;50:1289-97.
84. Boelaert JR, Weinberg GA, Weinberg ED. Altered iron metabolism in HIV infection: mechanisms, possible consequences, and proposals for management Infect Agents Dis. 1996;5:36-46.

85. Wessling-Resnick M. Crossing the iron gate: why and how transferrin receptors mediate viral entry. Annu Rev Nutr. 2018;38:431-58.

86. Demogines A, Abraham J, Choe H, Farzan M, Sawyer SL. Dual host-virus arms races shape an essential housekeeping protein. PLoS Biol. 2013;11:e1001571.

87. Kim BH, Jun YC, Jin JK, Kim Jl, Kim NH, Leibold EA, et al. Alteration of iron regulatory proteins (IRP1 and IRP2) and ferritin in the brains of scrapie-infected mice. Neurosci Lett. 2007;422:158-63.

88. Fillebeen C, Pantopoulos K. Iron inhibits replication of infectious hepatitis $C$ virus in permissive Huh7.5.1 cells. J Hepatol. 2010;53:995-9.

89. Wang H, Li Z, Niu J, Xu Y, Ma L, Lu A, et al. Antiviral effects of ferric ammonium citrate. Cell Discov. 2018;4:14.

90. Zhu Y, Tong L, Nie K, Wiwatanaratanabutr I, Sun P, Li Q, et al. Host serum iron modulates dengue virus acquisition by mosquitoes. Nat Microbiol. 2019; 4:2405-15.

91. Radoshitzky SR, Abraham J, Spiropoulou CF, Kuhn JH, Nguyen D, Li W, et al. Transferrin receptor 1 is a cellular receptor for New World haemorrhagic fever arenaviruses. Nature. 2007;446:92-6.

92. Hewitt EW. The MHC class I antigen presentation pathway: strategies for viral immune evasion. Immunology. 2003;110:163-9.

93. Ben-Arieh SV, Zimerman B, Smorodinsky NI, Yaacubovicz M, Schechter C, Bacik I, et al. Human cytomegalovirus protein US2 interferes with the expression of human HFE, a nonclassical class I major histocompatibility complex molecule that regulates iron homeostasis. J Virol. 2001;75:10557-62.

94. Parker JS, Parrish CR. Cellular uptake and infection by canine parvovirus involves rapid dynamin-regulated clathrin-mediated endocytosis, followed by slower intracellular trafficking. J Virol. 2000;74:1919-30.

95. Sarute N, Ross SR. New world arenavirus biology. Annu Rev Virol. 2017;4:141-58.

96. Tsujimoto $\mathrm{H}$, Anderson MAE, Myles KM, Adelman ZN. Identification of candidate iron transporters from the ZIP/ZnT gene families in the mosquito aedes aegypti. Front Physiol. 2018;9:380.

97. Martin DN, Uprichard SL. Identification of transferrin receptor 1 as a hepatitis $C$ virus entry factor. Proc Natl Acad Sci USA. 2013;110:10777-82.

98. Reshi ML, Su YC, Hong JR. RNA Viruses: ROS-mediated cell death. Int J Cell Biol. 2014;2014:467452.

99. Reshi L, Wu JL, Wang HV, Hong JR. Aquatic viruses induce host cell death pathways and its application. Virus Res. 2016;211:133-44.

100. Khan M, Syed GH, Kim SJ, Siddiqui A. Mitochondrial dynamics and viral infections: A close nexus. Biochim Biophys Acta. 2015;1853:2822-33.

101. Kwong JQ, Molkentin JD. Physiological and pathological roles of the mitochondrial permeability transition pore in the heart. Cell Metab. 2015;21:206-14.

102. Walter $\mathrm{PB}$, Knutson MD, Paler-Martinez A, Lee $\mathrm{S}, \mathrm{Xu} \mathrm{Y}$, Viteri FE, et al. Iron deficiency and iron excess damage mitochondria and mitochondrial DNA in rats. Proc Natl Acad Sci USA. 2002;99:2264-9.

103. Hino K, Nishina S, Sasaki K, Hara Y. Mitochondrial damage and iron metabolic dysregulation in hepatitis C virus infection. Free Radic Biol Med. 2019;133:193-9.

104. Seiler A, Schneider M, Förster H, Roth S, Wirth EK, Culmsee C, et al. Glutathione peroxidase 4 senses and translates oxidative stress into 12/15-lipoxygenase dependent- and AIF-mediated cell death. Cell Metab. 2008;8:237-48.

105. Pallast S, Arai K, Wang X, Lo EH, van Leyen K. 12/15-Lipoxygenase targets neuronal mitochondria under oxidative stress. J Neurochem. 2009;111:882-9.

106. Yuan H, Li X, Zhang X, Kang R, Tang D. Identification of ACSL4 as a biomarker and contributor of ferroptosis. Biochem Biophys Res Commun. 2016;478:1338-43.

107. Wiley SE, Murphy AN, Ross SA, van der Geer P, Dixon JE. MitoNEET is an ironcontaining outer mitochondrial membrane protein that regulates oxidative capacity. Proc Natl Acad Sci USA. 2007;104:5318-23.

108. Tamir S, Paddock ML, Darash-Yahana-Baram M, Holt SH, Sohn YS, Agranat L, et al. Structure-function analysis of NEET proteins uncovers their role as key regulators of iron and ROS homeostasis in health and disease. Biochim Biophys Acta. 2015;1853:1294-315.

109. Yuan H, Li X, Zhang X, Kang R, Tang D. CISD1 inhibits ferroptosis by protection against mitochondrial lipid peroxidation. Biochem Biophys Res Commun. 2016;478:838-44.

110. Moreno-Altamirano MMB, Kolstoe SE, Sanchez-Garcia FJ. Virus control of cell metabolism for replication and evasion of host immune responses. Front Cell Infect Microbiol. 2019;9:95.

111. Kurz T, Leake A, Von Zglinicki T, Brunk UT. Relocalized redox-active lysosomal iron is an important mediator of oxidative-stress-induced DNA damage. Biochem J. 2004:378:1039-45.

112. Kurz T, Terman A, Gustafsson B, Brunk UT. Lysosomes and oxidative stress in aging and apoptosis. Biochim Biophys Acta. 2008;1780:1291-303.

113. Appelqvist $H$, Waster $P$, Kagedal $K$, Ollinger $K$. The lysosome: from waste bag to potential therapeutic target. J Mol Cell Biol. 2013;5:214-26. 
114. Saftig P, Klumperman J. Lysosome biogenesis and lysosomal membrane proteins: trafficking meets function. Nat Rev Mol Cell Biol. 2009;10:623-35.

115. Aits S, Jaattela M. Lysosomal cell death at a glance. J Cell Sci. 2013;126:1905-12.

116. Asano T, Komatsu M, Yamaguchi-Iwai Y, Ishikawa F, Mizushima N, Iwai K. Distinct mechanisms of ferritin delivery to lysosomes in iron-depleted and iron-replete cells. Mol Cell Biol. 2011;31:2040-52.

117. Wang F, Gomez-Sintes R, Boya P. Lysosomal membrane permeabilization and cell death. Traffic. 2018;19:918-31.

118. Dixon SJ, Patel DN, Welsch M, Skouta R, Lee ED, Hayano M, et al. Pharmacological inhibition of cystine-glutamate exchange induces endoplasmic reticulum stress and ferroptosis. eLife. 2014;3:e02523.

119. Gout PW, Buckley AR, Simms CR, Bruchovsky N. Sulfasalazine, a potent suppressor of lymphoma growth by inhibition of the $\mathrm{x}(\mathrm{c})$ - cystine transporter: a new action for an old drug. Leukemia. 2001;15:1633-40.

120. Lu SC. Glutathione synthesis. Biochim Biophys Acta. 2013;1830:3143-53.

121. Jiang L, Hickman JH, Wang SJ, Gu W. Dynamic roles of p53-mediated metabolic activities in ROS-induced stress responses. Cell Cycle. 2015;14:2881-5.

122. Sato $H$, Tamba M, Ishii T, Bannai S. Cloning and expression of a plasma membrane cystine/glutamate exchange transporter composed of two distinct proteins. J Biol Chem. 1999;274:11455-8.

123. Jiang L, Kon N, Li T, Wang SJ, Su T, Hibshoosh H, et al. Ferroptosis as a p53mediated activity during tumour suppression. Nature. 2015;520:57-62.

124. Nguyen D, Alavi MV, Kim KY, Kang T, Scott RT, Noh YH, et al. A new vicious cycle involving glutamate excitotoxicity, oxidative stress and mitochondrial dynamics. Cell Death Dis. 2011;2:e240.

125. de Groot J, Sontheimer H. Glutamate and the biology of gliomas. Glia. 2011; 59:1181-9.

126. Zhou Y, Wang X, Tzingounis AV, Danbolt NC, Larsson HP. EAAT2 (GLT-1; slc1a2) glutamate transporters reconstituted in liposomes argues against heteroexchange being substantially faster than net uptake. J Neurosci. 2014;34:13472-85.

127. Carr M, Gonzalez G, Martinelli A, Wastika CE, Ito K, Orba Y, et al. Upregulated expression of the antioxidant sestrin 2 identified by transcriptomic analysis of Japanese encephalitis virus-infected SH-SY5Y neuroblastoma cells. Virus Genes. 2019;55:630-42.

128. Dai L, Cao Y, Chen Y, Parsons C, Qin Z. Targeting xCT, a cystine-glutamate transporter induces apoptosis and tumor regression for KSHV/HIV-associated lymphoma. J Hematol Oncol. 2014;7:30.

129. Meister A, Anderson ME. Glutathione. Annu Rev Biochem. 1983;52:711-60.

130. Aquilano K, Baldelli S, Ciriolo MR. Glutathione: new roles in redox signaling for an old antioxidant. Front Pharmacol. 2014;5:196.

131. Lambert AJ, Brand MD. Reactive oxygen species production by mitochondria. Methods Mol Biol. 2009;554:165-81.

132. Rada B, Leto TL. Oxidative innate immune defenses by Nox/Duox family NADPH oxidases. Contrib Microbiol. 2008;15:164-87.

133. Molteni CG, Principi N, Esposito S. Reactive oxygen and nitrogen species during viral infections. Free Radic Res. 2014;48:1163-9.

134. Morris D, Guerra C, Donohue C, Oh H, Khurasany M, Venketaraman V. Unveiling the mechanisms for decreased glutathione in individuals with HIV infection. Clin Dev Immunol. 2012;2012:734125.

135. Brill KJ, Li Q, Larkin R, Canaday DH, Kaplan DR, Boom WH, et al. Human natural killer cells mediate killing of intracellular Mycobacterium tuberculosis H37Rv via granule-independent mechanisms. Infect Immun. 2001;69:1755-65.

136. Papi A, Contoli M, Gasparini P, Bristot L, Edwards MR, Chicca M, et al. Role of xanthine oxidase activation and reduced glutathione depletion in rhinovirus induction of inflammation in respiratory epithelial cells. J Biol Chem. 2008; 283:28595-606

137. van der Linden WA, Schulze $C J$, Herbert AS, Krause TB, Wirchnianski AA, Dye JM, et al. Cysteine cathepsin inhibitors as anti-ebola agents. ACS Infect Dis. 2016;2:173-9.

138. Zhang $\mathrm{HQ}$, Zhang JQ, Forman $\mathrm{H}$. Down regulation of glutathione and glutamate cysteine ligase in the inflammatory response of macrophages. Free Radic Bio Med. 2018;128:S113-S.

139. Zhang H, Zhou L, Yuen J, Birkner N, Leppert V, O'Day PA, et al. Delayed Nrf2regulated antioxidant gene induction in response to silica nanoparticles. Free Radic Bio Med. 2017;108:311-9.

140. Zhang H, Liu H, Zhou L, Yuen J, Forman HJ. Temporal changes in glutathione biosynthesis during the lipopolysaccharide-induced inflammatory response of THP-1 macrophages. Free Radic Bio Med. 2017;113:304-10.

141. Gladyshev VN, Stadtman TC, Hatfield DL, Jeang KT. Levels of major selenoproteins in T cells decrease during HIV infection and low molecular mass selenium compounds increase. Proc Natl Acad Sci USA. 1999:96:835-9.

142. Shisler JL, Senkevich TG, Berry MJ, Moss B. Ultraviolet-induced cell death blocked by a selenoprotein from a human dermatotropic poxvirus. Science. 1998;279:102-5.

143. Tang D, Chen X, Kang R, Kroemer G. Ferroptosis: molecular mechanisms and health implications. Cell Res. 2021:31:107-25.
144. Richards JT, Katz ME, Kern ER. Topical butylated hydroxytoluene treatment of genital herpes simplex virus infections of guinea pigs. Antivir Res. 1985;5:281-90.

145. Spada C, Treitinger A, Reis M, Masokawa IY, Verdi JC, Luiz MC, et al. An evaluation of antiretroviral therapy associated with alpha-tocopherol supplementation in HIV-infected patients. Clin Chem Lab Med. 2002;40:456-9.

146. Wang L, Wang Y, Ye D, Liu Q. Review of the 2019 novel coronavirus (SARS-CoV2) based on current evidence. Int J Antimicrob Agents. 2020;55:105948.

147. Creek DJ, Charman WN, Chiu FC, Prankerd RJ, McCullough KJ, Dong Y, et al. Ironmediated degradation kinetics of substituted dispiro-1,2,4-trioxolane antimalarials. J Pharm Sci. 2007;96:2945-56.

148. Efferth T, Romero MR, Wolf DG, Stamminger T, Marin JJ, Marschall M. The antiviral activities of artemisinin and artesunate. Clin Infect Dis. 2008;47:804-11.

149. Zhou Y, Gilmore K, Ramirez S, Settels E, Gammeltoft KA, Pham LV, et al. In vitro efficacy of artemisinin-based treatments against SARS-CoV-2. Sci Rep. 2021;11:14571.

150. Di Bisceglie AM, Axiotis CA, Hoofnagle JH, Bacon BR. Measurements of iron status in patients with chronic hepatitis. Gastroenterology.1992;102:2108-13.

151. Edeas M, Saleh J, Peyssonnaux C. Iron: Innocent bystander or vicious culprit in COVID-19 pathogenesis? Int J Infect Dis. 2020;97:303-5.

152. Cavezzi A, Troiani E, Corrao S. COVID-19: hemoglobin, iron, and hypoxia beyond inflammation. A narrative review. Clin Pr. 2020;10:1271.

153. Redig AJ, Berliner N. Pathogenesis and clinical implications of HIV-related anemia in 2013. Hematol Am Soc Hematol Educ Program. 2013;2013:377-81.

154. Duchemin JB, Paradkar PN. Iron availability affects West Nile virus infection in its mosquito vector. Virol J. 2017;14:103.

155. Salimi V, Ramezani A, Mirzaei H, Tahamtan A, Faghihloo E, Rezaei F, et al. Evaluation of the expression level of 12/15 lipoxygenase and the related inflammatory factors (CCL5, CCL3) in respiratory syncytial virus infection in mice model. Micro Pathog. 2017;109:209-13.

156. Kumar R, Nayak M, Sahoo GC, Pandey K, Sarkar MC, Ansari Y, et al. Iron oxide nanoparticles based antiviral activity of H1N1 influenza A virus. J Infect Chemother. 2019;25:325-9.

157. Lin TY, Chu C, Chiu CH. Lactoferrin inhibits enterovirus 71 infection of human embryonal rhabdomyosarcoma cells in vitro. J Infect Dis. 2002;186:1161-4.

158. Fujita $N$, Takei Ylron. hepatitis $C$ virus, and hepatocellular carcinoma: iron reduction preaches the gospel for chronic hepatitis C. J Gastroenterol. 2007;42:923-6.

159. Polonikov A. Endogenous deficiency of glutathione as the most likely cause of serious manifestations and death in COVID-19 patients. ACS Infect Dis. 2020;6:1558-62.

160. Wang J, Chen $Y$, Gao N, Wang $Y$, Tian $Y, W u$ J, et al. Inhibitory effect of glutathione on oxidative liver injury induced by dengue virus serotype 2 infections in mice. PLoS One. 2013;8:e55407.

161. Bridges $C C, H u H$, Miyauchi $S$, Siddaramappa UN, Ganapathy $M E$, Ignatowicz $L$, et al. Induction of cystine-glutamate transporter xc- by human immunodeficiency virus type 1 transactivator protein tat in retinal pigment epithelium. Invest Ophthalmol Vis Sci. 2004;45:2906-14.

162. Matthias LJ, Yam PT, Jiang XM, Vandegraaff $N$, Li $P$, Poumbourios $P$, et al. Disulfide exchange in domain 2 of CD4 is required for entry of HIV-1. Nat Immunol. 2002;3:727-32.

163. Sebastiano M, Chastel O, de Thoisy B, Eens M, Costantini D. Oxidative stress favours herpes virus infection in vertebrates: a meta-analysis. Curr Zool. 2016;62:325-32.

164. Palamara AT, Perno CF, Ciriolo MR, Dini L, Balestra E, D'Agostini C, et al. Evidence for antiviral activity of glutathione: in vitro inhibition of herpes simplex virus type 1 replication. Antivir Res. 1995;27:237-53.

165. Nencioni L, luvara A, Aquilano K, Ciriolo MR, Cozzolino F, Rotilio G, et al. Influenza $A$ virus replication is dependent on an antioxidant pathway that involves GSH and Bcl-2. FASEB J. 2003;17:758-60.

166. Alsuwaidi AR, Almarzooqi S, Albawardi A, Benedict S, Kochiyil J, Mustafa F, et al. Cellular bioenergetics, caspase activity and glutathione in murine lungs infected with influenza A virus. Virology. 2013;446:180-8.

167. Kumar S, Misra UK, Kalita J, Khanna VK, Khan MY. Imbalance in oxidant/antioxidant system in different brain regions of rat after the infection of Japanese encephalitis virus. Neurochem Int. 2009;55:648-54.

168. Chauhan PS, Misra UK, Kalita J. A study of glutamate levels, NR1, NR2A, NR2B receptors and oxidative stress in rat model of Japanese encephalitis. Physiol Behav. 2017;171:256-67.

169. Vasireddi M, Crum A, May H, Katz D, Hilliard J. A novel antiviral inhibits Zika virus infection while increasing intracellular glutathione biosynthesis in distinct cell culture models. Antivir Res. 2019;161:46-52.

170. Bharadwaj M, Khanna N, Mathur A, Chaturvedi UC. Effect of macrophagederived factor on hypoferraemia induced by Japanese encephalitis virus in mice. Clin Exp Immunol. 1991;83:215-8.

171. Yue Y, Nabar NR, Shi CS, Kamenyeva O, Xiao X, Hwang IY, et al. SARS-coronavirus open reading frame-3a drives multimodal necrotic cell death. Cell Death Dis. 2018;9:904. 
172. Martin DN, Uprichard SL. Identification of transferrin receptor 1 as a hepatitis $C$ virus entry factor. Proc Natl Acad Sci USA. 2013;110:10777-82.

173. Zeltina A, Krumm SA, Sahin M, Struwe WB, Harlos K, Nunberg JH, et al. Convergent immunological solutions to Argentine hemorrhagic fever virus neutralization. Proc Natl Acad Sci USA. 2017;114:7031-6.

174. Zong M, Fofana I, Choe $\mathrm{H}$. Human and host species transferrin receptor 1 use by North American Arenaviruses. J Virol. 2014;88:9418-28.

175. Radoshitzky SR, Longobardi LE, Kuhn JH, Retterer C, Dong L, Clester JC, et al. Machupo virus glycoprotein determinants for human transferrin receptor 1 binding and cell entry. PLoS One. 2011;6:e21398.

176. Rojek JM, Kunz S. Cell entry by human pathogenic arenaviruses. Cell Microbiol. 2008;10:828-35.

177. Fedeli $\mathrm{C}$, Moreno $\mathrm{H}$, Kunz $\mathrm{S}$. Novel insights into cell entry of emerging human pathogenic arenaviruses. J Mol Biol. 2018;430:1839-52.

178. Rojek JM, Sanchez AB, Nguyen NT, de la Torre JC, Kunz S. Different mechanisms of cell entry by human-pathogenic Old World and New World arenaviruses. J Virol. 2008;82:7677-87.

179. Zhang S, Hu W, Yuan L, Yang Q. Transferrin receptor 1 is a supplementary receptor that assists transmissible gastroenteritis virus entry into porcine intestinal epithelium. Cell Commun Signal. 2018;16:69.

180. Ross SR, Schofield JJ, Farr CJ, Bucan M. Mouse transferrin receptor 1 is the cell entry receptor for mouse mammary tumor virus. Proc Natl Acad Sci USA. 2002;99:12386-90.

181. Rose PP, Hanna SL, Spiridigliozzi A, Wannissorn N, Beiting DP, Ross SR, et al. Natural resistance-associated macrophage protein is a cellular receptor for sindbis virus in both insect and mammalian hosts. Cell Host Microbe. 2011; 10:97-104.

182. Fang $X$, Wang $H$, Han $D$, Xie $E$, Yang $X$, Wei J, et al. Ferroptosis as a target for protection against cardiomyopathy. Proc Natl Acad Sci USA. 2019;116:2672-80.

183. Torii S, Shintoku R, Kubota C, Yaegashi M, Torii R, Sasaki M, et al. An essential role for functional lysosomes in ferroptosis of cancer cells. Biochem J. 2016:473:769-77.

184. Gao H, Bai Y, Jia Y, Zhao Y, Kang R, Tang D, et al. Ferroptosis is a lysosomal cell death process. Biochem Biophys Res Commun. 2018:503:1550-6.

185. Radisky DC, Kaplan J. Iron in cytosolic ferritin can be recycled through lysosomal degradation in human fibroblasts. Biochem J. 1998;336(Pt 1):201-5.
186. Chen MS, Wang SF, Hsu CY, Yin PH, Yeh TS, Lee HC, et al. CHAC1 degradation of glutathione enhances cystine-starvation-induced necroptosis and ferroptosis in human triple negative breast cancer cells via the GCN2-elF2alpha-ATF4 pathway. Oncotarget. 2017;8:114588-602.

187. Hoyer-Hansen M, Jaattela M. Connecting endoplasmic reticulum stress to autophagy by unfolded protein response and calcium. Cell Death Differ. 2007; 14:1576-82.

188. Adedoyin O, Boddu R, Traylor A, Lever JM, Bolisetty S, George JF, et al. Heme oxygenase-1 mitigates ferroptosis in renal proximal tubule cells. Am J Physiol Ren Physiol. 2018;314:F702-14.

189. Song X, Xie Y, Kang R, Hou W, Sun X, Epperly MW, et al. FANCD2 protects against bone marrow injury from ferroptosis. Biochem Biophys Res Commun. 2016; 480:443-9.

190. Galluzzi L, Bravo-San Pedro JM, Kroemer G. Ferroptosis in p53-dependent oncosuppression and organismal homeostasis. Cell Death Differ. 2015;22: 1237-8.

191. Zhou L, Zhao B, Zhang L, Wang S, Dong D, Lv H, et al. Alterations in Cellular Iron Metabolism Provide More Therapeutic Opportunities for Cancer. Int J Mol Sci. 2018;19:1545.

192. Matsushita M, Freigang S, Schneider C, Conrad M, Bornkamm GW, Kopf M. T cell lipid peroxidation induces ferroptosis and prevents immunity to infection. J Exp Med. 2015;212:555-68.

193. Kang R, Zeng L, Zhu S, Xie Y, Liu J, Wen Q, et al. Lipid peroxidation drives gasdermin D-mediated pyroptosis in lethal polymicrobial sepsis. Cell Host Microbe. 2018;24:97-108 e4.

194. Jia M, Qin D, Zhao C, Chai L, Yu Z, Wang W, et al. Redox homeostasis maintained by GPX4 facilitates STING activation. Nat Immunol. 2020;21:727-35.

195. Avery JC, Hoffmann PR. Selenium, Selenoproteins, and Immunity. Nutrients. 2018;10:1203.

196. Shrimali RK, Irons RD, Carlson BA, Sano Y, Gladyshev VN, Park JM, et al. Selenoproteins mediate $\mathrm{T}$ cell immunity through an antioxidant mechanism. J Biol Chem. 2008;283:20181-5.

197. Li C, Deng X, Xie X, Liu Y, Friedmann Angeli JP, Lai L. Activation of glutathione peroxidase 4 as a novel anti-inflammatory strategy. Front Pharmacol. 2018; 9:1120. 